www.jmscr.igmpublication.org Impact Factor 5.244

Index Copernicus Value: 5.88 ISSN (e)-2347-176x ISSN (p) 2455-0450 crossref DOI:_http://dx.doi.org/10.18535/jmscr/v4i6.26

\title{
Effect of Intravenous Fentanyl and Magnesium Sulphate in General Anesthesia and Surgery During Peri-Operative Period - A Randomized Comparative Study
}

\author{
Authors \\ Dr K. Rajarajeswaran M.B.B.S.,M.D ${ }^{1}$, Dr S. Sivakumar M.B.B.S.,M.D ${ }^{2}$ \\ ${ }_{1,2}$ Assistant Professor, Department of Anesthesia and Critical Care \\ Madha Medical College Hospital and Research Institute, Chennai \\ Email:drshiva187@gmail.com
}

\begin{abstract}
Aim and Background: Success of all major and specialized surgical procedures under general anesthesia depends on balanced anaesthetic techniques, with minimal hemodynamic disturbance to the patients. Aim of this study is to compare the hemodynamic effects of intravenous Magnesium sulfate \& Fentanyl citrate in surgical procedures, under general anaesthesia during intubation, intra-operative and postoperative period and their significant side effects if any.

Methods and Materials: This prospective, randomized study was carried out on 60 ASA grade I or II patients, scheduled for elective surgeries, requiring general anaesthesia with endotracheal intubation. 2 groups of 30 each. F Group - Patients were given Fentanyl citrate. M Group - Patients were given Magnesium sulfate as the study drug.

Results: Mean change in pulse rate and mean arterial pressure (MAP) after intubation was more for $M$ Group. Pulse rate and MAP reached near baseline value at 5 minutes after intubation in $F$ group, while in 10 min. after intubatio $n$ in $M$ group. 3 hrs after surgery all the patients in $F$ group were given first dose of analgesic but in $M$ group, only 2 and 10 patients were given first dose of analgesic while 3 and 15 patients were having no pain and mild pain respectively.

Conclusion: Magnesium sulfate provides intra-operative hemodynamic stability like fentanyl citrate, though not superior to that provided by Fentanyl citrate. Magnesium sulfate can be considered as a useful and good alternative to Fentanyl citrate, especially in circumstances, where the complications associated with opioids are undesirable.

Keywords: Intubation.Magnesium sulphate. Fentayl. Mean arterial pressure,Post operative pain
\end{abstract}

\section{INTRODUCTION}

Laryngoscopy \& Tracheal intubation are noxious stimuli that evoke a transient but marked sympathetic response manifesting as increase in heart rate, blood pressure and arrhythmias ${ }^{[1]}$. These physiological changes are well tolerated by healthy individuals. However these changes may be detrimental or even fatal in patients with coronary artery disease, hypertension, cerebrovascular disease, intracranial aneurysm and valvular heart disease ${ }^{[1,2]}$. Thus attempts must be made to prevent the pressor response to 
laryngoscopy and intubation and so, anaesthesiologists are in search of safest and the most efficient drug which can prevent cardiovascular response to the laryngoscopy and tracheal intubation. A number of drugs \& techniques have been used in an attempt to attenuate these undesirable hemodynamic responses. These include Deepening of AnaesthesiA ${ }^{[1]}$. Lidocaine spray ${ }^{[2]}$, Opioids ${ }^{[3]}$, Droperidol [3] PropanoloL [4], Nitroglycerine ointment and isosorbide dinitrate ${ }^{[4]}$, Calcium channel blocker ${ }^{[5]}$. Lidocaine is the drug used most. Recent studies have questioned its efficacy. In clinical practice, it is particularly effective in preventing the pressor response to tracheal intubation, whatever its route of administration (intravenous or intratracheal), but not the increase in heart rate. Beta blockers with bradycardic, antihypertensive, antiarrhythmic and antiischaemic properties, have been advocated. As opposed to lidocaine, these agents are more effective in preventing the changes in heart rate than the pressor response. Thus, a number of drugs to prevent the pressor response to laryngoscopy and intubation have been recommended and used; however only a few pharmacological approaches have been found satisfactory. Moreover, severe post operative pain is the most common and the most distressing complication of surgery for an anaesthesiologist. Although surgical pain is well controlled, the post operative pain is still poorly treated. Despite the introduction of new analgesics for pain relief, the advances of post operative pain relief still depends on the improvement in the delivery of existing drugs to the patients. Relief from severe pain arising from deep or visceral structures, as happens in surgical procedures, requires the use of opioids. Fentanyl is a potent narcotic analgesic; a $100 \mathrm{mcg}$ dose of Fentanyl is equivalent in analgesic activity to $10 \mathrm{mg}$ of Morphine. It also causes attenuation of cardiovascular, hormonal \& metabolic responses to stress, as occurs after laryngoscopy \& endotracheal intubation $\&$ as is reflected in rise in pulse rate \& BP after laryngoscopy \& endotracheal intubation ${ }^{[6]}$. Other than opioids like Fentanyl, Magnesium sulfate is also used as perioperative analgesic due to its antagonistic effect on NMDA (N- Methyl, DAspartate) receptors \& Calcium ion channel ${ }^{[7]}$. Magnesium inhibits catecholamine release from adrenergic nerve terminals \& adrenal medulla during laryngoscopy \& endotracheal intubation ${ }^{[7]}$. The present study was designed to study and compare the hemodynamic effects and postoperative analgesic effect of intravenous Magnesium sulfate and Fentanyl citrate in surgical procedures, under general anaesthesia.

\section{METHODS AND MATERIALS}

Following approval from the institutional ethical committee and a written informed consent, this prospective, randomized study was carried out on 60 ASA grade I or II patients, of either sex, aged 18-45 years, scheduled for elective surgeries, requiring general anaesthesia with endotracheal intubation. The patients were, then, randomly divided in 2 groups of 30 each.

Inclusion criteria: Patients with ASA grade I and II, Patients of age group 18-45 years, Patients of either sex, Patients undergoing elective surgical procedures under general anesthesia, surgical procedures lasting upto 90 minutes.

Exclusion criteria: Surgical procedures, lasting > 90 min, ASA grade III or above, Patients having compromised pulmonary status (eg. COPD, bronchial asthma), Patients with compromised cardiac status (Heart block, hypertension, cardiac failure), Patients with impaired LFT and/ or RFT, Patients on medications like $\beta$-blockers calcium channel blockers, hypnotics or narcotic analgesics, Diabetic patients. F Group- Patients were given Fentanyl citrate as the study drug. Initial $(5 \mathrm{~min}$. before induction) $1.25 \mathrm{mcg} / \mathrm{kg}$, Subsequent (5 min. before incision and every $30 \mathrm{~min} .0 .5 \mathrm{mcg} / \mathrm{kg}$ given. M Group- Patients were given Magnesium sulfate as the study drug. Initial $(5 \mathrm{~min}$. before induction) $20 \mathrm{mg} / \mathrm{kg}$, Subsequent (5 min. before incision and every $30 \mathrm{~min} .10 \mathrm{mg} / \mathrm{kg}$ given. 
On arrival in the OT, intravenous line was taken and ringer lactate infusion was started. Baseline Vitals parameters- Pulse rate, BP (systolic and diastolic) and ECG were recorded. Mean arterial pressure (MAP) was calculated. Patients were premedicated with Inj. Glycopyrrolate $0.2 \mathrm{mg}$ i.v. Calculated volume of the study drug (according to the initial dose given in the above table) was first diluted in a $10 \mathrm{ml}$ syringe and then was injected slowly over a period of $2 \mathrm{~min}$. Induction was done five minutes after the initial dose of study drug, during which the patient was preoxygenated with $100 \% \mathrm{O}_{2}$. Induction was done using Inj. Thiopentone sodium (2.5\% solution) $5 \mathrm{mg} / \mathrm{kg}$ slow i.v. Intubation was facilitated with Inj. Succinylcholine $2 \mathrm{mg} / \mathrm{kg}$. One minute after injecting Succinylcholine, laryngoscopy and endotracheal intubation was performed. Anaesthesia was maintained by ventilating with $\mathrm{O}_{2}: \mathrm{N}_{2} \mathrm{O}(33 \%: 66 \%)$ and $0.2 \%$ Halothane, using Bain's circuit. Muscle relaxation was provided with nondepolarizing muscle relaxant [Atracurium $0.3 \mathrm{mg} / \mathrm{kg}$ (loading dose) and $0.1 \mathrm{mg} / \mathrm{kg}$ (maintenance dose)]. Study drug was diluted and repeated slowly, (as per dose given) after intubation, that is five minutes before skin incision and at every 30 minutes interval thereafter, till the completion of surgery. PR, SBP, DBP- at $\mathrm{O}$ min. (basal value), 5 minutes after study drug (initial dose), immediately after intubation, at 5, 10, 20, 30, 45, 60, 75 and 90 minutes after intubation. After completion of surgery, residual neuromuscular blockage was reversed with Inj. Glycopyrrolate $0.5 \mathrm{mg}$ and Neostigmine $2.5 \mathrm{mg}$. Inj. Tramadol was used as sole analgesic, as and when required postoperatively, and the total amount of Inj. Tramadol given within 6 hours after completion of surgery was recorded. Postoperative Pain was measured by using standardized Visual Analogue Scale (VAS)(0-10 scale 0 - no pain 10 - worst pain) \& Verbal Rating Score (VRS)( $0-4$ scale 0 - no pain 4 - very sever pain ) at $0,1^{\text {st }}, 3^{\text {rd }} \& 6^{\text {th }}$ hour postoperatively. VAS score of $>3$ or VRS score $>2$ was considered inadequate analgesia.
Statistical analysis- All the quantitative data were summarized in the form of Mean \pm SD. The difference between mean value of both groups were analyzed using Student ' $t$ ' test. All the qualitative data were summarized in form of proportions. The differences between proportions were analyzed using Chi square test.P values $<0.05$ were considered as Significant $(\mathrm{S})$ and $\mathrm{P}$ value $>0.05$ as statistically Non Significant (NS).

\section{RESULTS}

It was observed that mean baseline variables were similar in both the groups and no statistically significant difference was present, except pulse rate [TABLE 1]. In $F$ Group, there was statistically insignificant fall $(0.93 \%)$ in pulse rate 5 minutes after study drug; and statistically significant rise $(6.90 \%)$ immediately after intubation. The value of pulse rate reached near baseline value at 5 minutes after intubation and then remained near baseline value throughout the surgery. In M Group, there was statistically significant $(9.99 \%)$ rise in pulse rate 5 minutes after study drug; and also statistically significant $(15.00 \%)$ rise after intubation; which reached near baseline values at 10 minutes after intubation and then remained near baseline value throughout the surgery. It was observed that (a) 5 min. after study drug, pulse rate decreased in $F$ group (insignificantly) but increased significantly in $\mathrm{M}$ group $(9.99 \%$ ) (b) Mean change in pulse rate after intubation was more for M Group (c) Pulse rate reached near baseline value at 5 minutes after intubation in $\mathrm{F}$ group, while in $10 \mathrm{~min}$. after intubation in $\mathrm{M}$ group [FIG 1]

In F Group, 5 minutes after study drug, there was clinically slight change in SBP; but immediately after intubation, there was statistically significant (3.90\%) rise in SBP (Systolic Blood Pressure); which reached near baseline value in 5 minutes after intubation and then remained near baseline value throughout the surgery. In M Group, 5 minutes after study drug, there was statistically significant $(1.29 \%)$ fall in SBP; but statistically significant $(5.49 \%)$ rise in SBP immediately after 
intubation; which reached near baseline value at 10 minutes after intubation, and then SBP remained near baseline value throughout surgery. It was observed that (a) 5 min. after study drug, there was significant fall in SBP in $M$ group $(1.29 \%)$ but there was insignificant change in $\mathrm{F}$ group $(0.03 \%)$ (b) Mean change in SBP after intubation was more for M Group (c) SBP reached near baseline value at 10 minutes after intubation in both the groups. In F Group, 5 minutes after study drug, there was statistically insignificant $(1.11 \%)$ fall in DBP; but immediately after intubation, there was statistically significant (4.62\%) rise in DBP (Diastolic Blood Pressure); which reached near baseline value in 5 minutes after intubation and then remained near baseline value most of the times during surgery. In $M$ Group, 5 minutes after study drug, there was statistically significant (2.27\%) fall in DBP; but statistically significant $(6.59 \%)$ rise in DBP immediately after intubation; which reached near baseline value at 5 minutes after intubation, and then DBP remained near baseline value most of the times during surgery. It was observed that (a) 5 min. after study drug, DBP decreased in F group (insignificantly) but decreased significantly in $\mathrm{M}$ group (9.99\%) (b) Mean change in DBP after intubation was more for $\mathrm{M}$ Group (c) DBP reached near baseline value at 5 minutes after intubation in both the groups. In F Group, there was a statistically significant $(0.61 \%)$ fall in MAP 5 minutes after study drug; but statistically significant $(4.28 \%)$ rise in MAP immediately after intubation; which reached near the baseline value at 5 minutes after intubation and then remained near baseline value throughout the surgery. In M Group, there was statistically significant $(1.96 \%)$ fall in MAP 5 minutes after study drug; but statistically significant $(6.11 \%)$ rise in MAP after intubation; which reached near baseline value at 10 minutes after intubation and then remained near baseline value throughout the surgery. It was observed that (a) 5 min. after study drug, the fall in MAP was more in $\mathrm{M}$ group $(1.96 \%$ ) than $\mathrm{F}$ group $(0.61 \%)$ (b) Mean change in MAP after intubation, was more for M Group (c) MAP reached near baseline value at 5 minutes after intubation in $\mathrm{F}$ group, while in $10 \mathrm{~min}$. after intubation in M group[FIGURE 2].

It was found that there was mild pain at the completion of surgery in 7 patients in $\mathrm{F}$ group and in 2 patients in $\mathrm{M}$ group. Rest patients were not having pain at the end of surgery. But at 1 hour after surgery, 19 and 11 patients in $\mathrm{F}$ group were having moderate and severe pain respectively, so were given analgesic (Inj. Tramadol); while in $\mathbf{M}$ group, 5 patients were having mild pain and rest were having no pain. At 3 hours post operative, all the patients in $\mathrm{F}$ group were already given first dose of analgesic and were having no pain but in M group, 2 and 10 patients were having moderate and severe pain respectively, so were given first dose of analgesic while 3 and 15 patients were having no pain and mild pain respectively. At 6 hours post operative, all the patients in both the groups were already given the first dose of analgesic, that is, Inj. Tramadol (100 mg) and none of the patients was having the complaint of pain again, in both the groups. It was observed that the pain relief by Magnesium sulfate was significantly longer lasting than that of Fentanyl citrate[TABLE 2].

Post operative Side effects and Complications - In the F group , $6.67 \%$ of the patients were having the complaint of nausea; $10 \%$ had vomiting; $13.33 \%$ were sedated and $10 \%$ complained of restlessness. In $\mathrm{M}$ group, $13.33 \%$ of the patients were having the complaint of nausea; $6.67 \%$ had vomiting; $6.67 \%$ had shivering and $6.67 \%$ complained of restlessness[FIG 3]. 
FIGURE 1 - Comparison of Mean change in Pulse Rate (from pre-op. value) in both groups

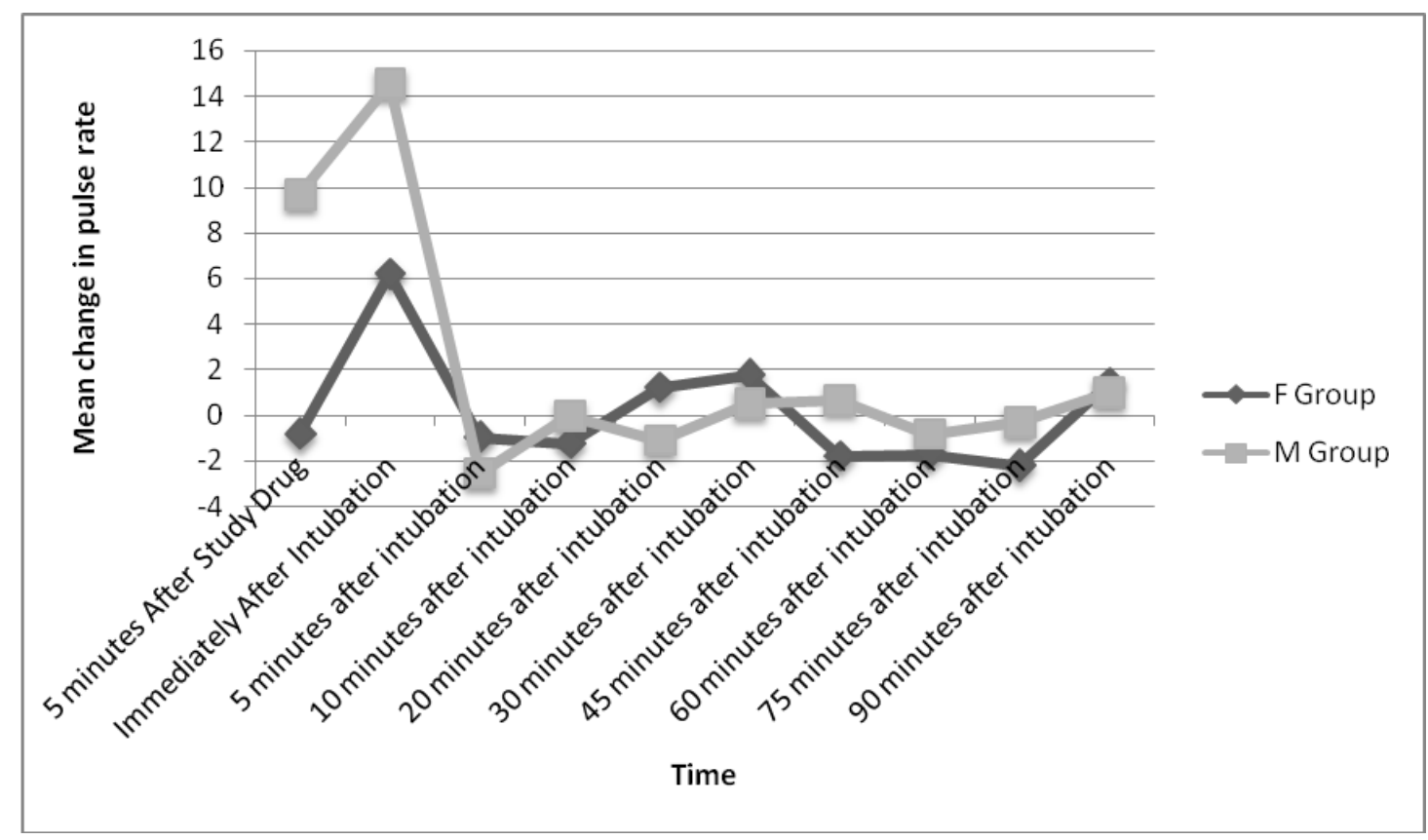

Figure 2 - Comparison of Mean change in MAP (from pre-op. value) in both groups

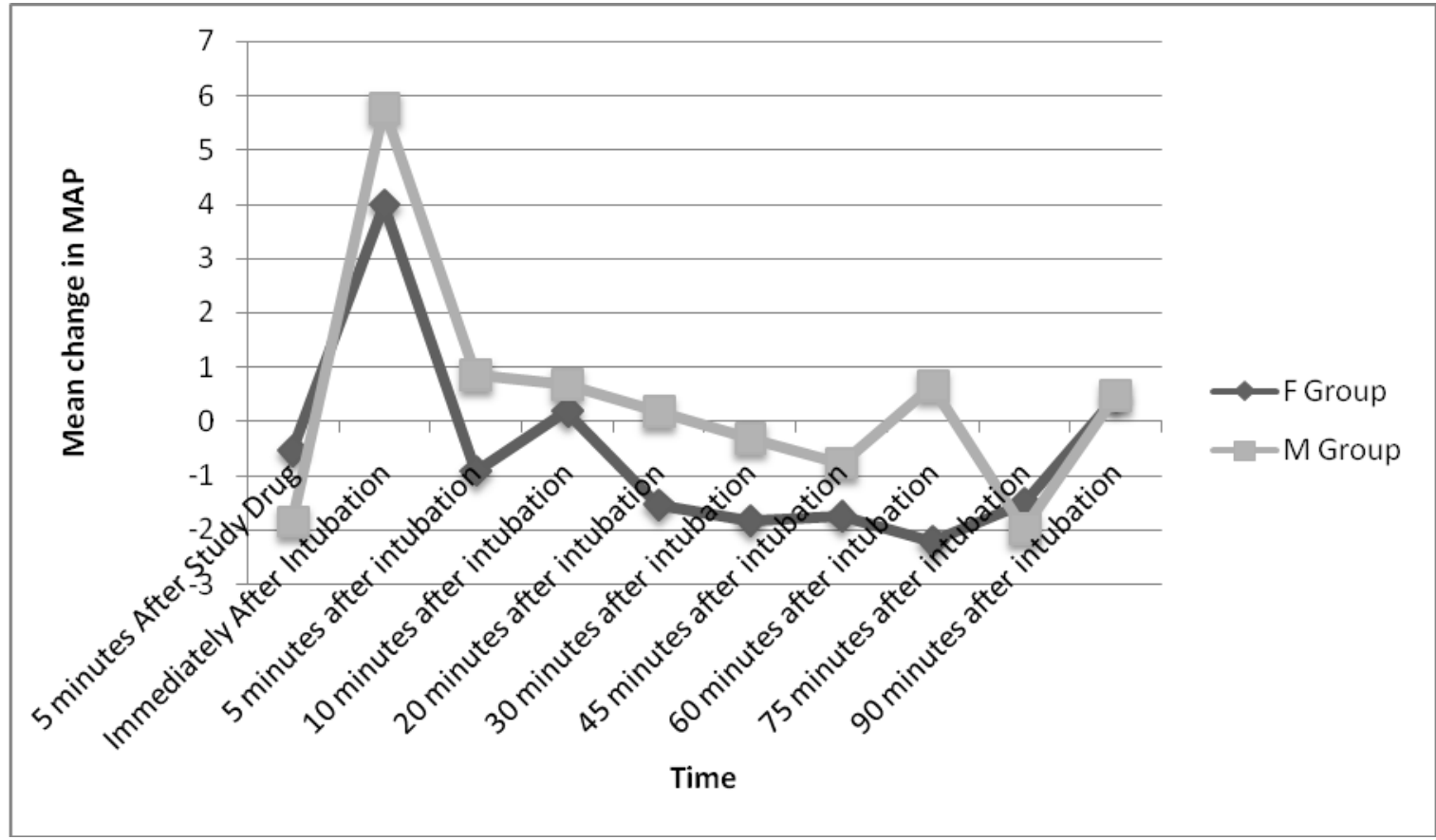


Figure 3 - Post operative Side effects and Complications

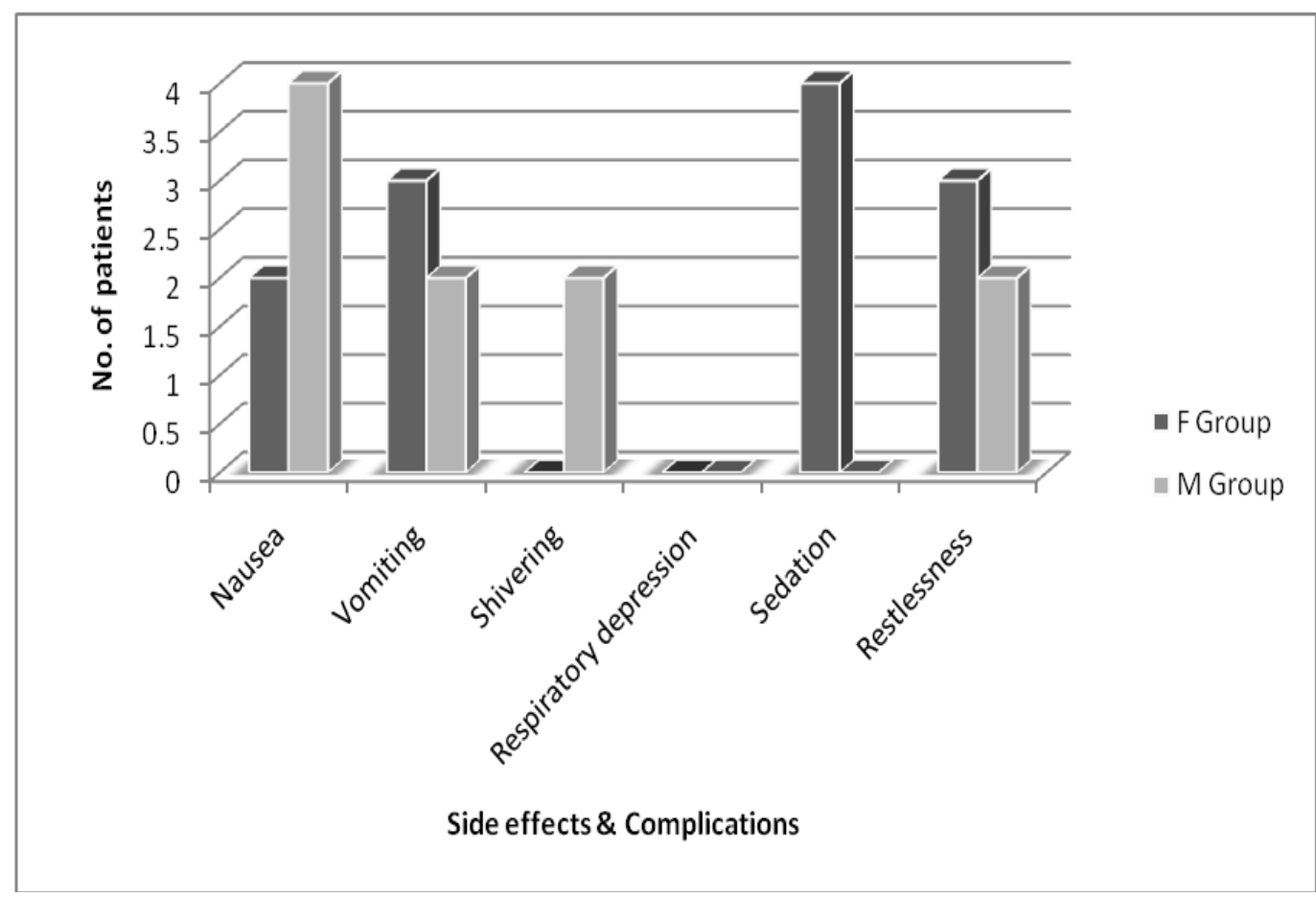

TABLE 1 - Comparison of Mean Baseline Variables in both the groups

\begin{tabular}{|l|l|l|l|l|}
\hline & Baseline PR & Baseline SBP & Baseline DBP & Baseline MAP \\
\hline F Group & $89.37 \pm 9.55$ & $122.30 \pm 7.93$ & $77.97 \pm 7.05$ & $92.74 \pm 6.82$ \\
\hline M Group & $97.10 \pm 11.81$ & $123.87 \pm 7.61$ & $79.47 \pm 5.56$ & $94.27 \pm 5.52$ \\
\hline P value & 0.0071 & 0.4380 & 0.3638 & 0.3463 \\
\hline Significance & S & NS & NS & NS \\
\hline
\end{tabular}

TABLE 2 - Comparison of Pain Assessment in Post operative Period

\begin{tabular}{|c|c|c|c|}
\hline $\begin{array}{l}\text { Time of Pain Assessment (In } \\
\text { Post op. period) }\end{array}$ & Severity of Pain & $\begin{array}{l}\text { F Group (No. of } \\
\text { patients) }\end{array}$ & $\begin{array}{l}\text { M Group (No. of } \\
\text { patients) }\end{array}$ \\
\hline \multirow{4}{*}{ At 0 Hours } & No Pain & 23 & 28 \\
\hline & Mild Pain & 7 & 2 \\
\hline & Moderate Pain & 0 & 0 \\
\hline & Severe Pain & 0 & 0 \\
\hline \multirow{4}{*}{ At 1 Hours } & No Pain & 0 & 25 \\
\hline & Mild Pain & 0 & 5 \\
\hline & Moderate Pain & 19 & 0 \\
\hline & Severe Pain & 11 & 0 \\
\hline \multirow{4}{*}{ At 3 Hours } & No Pain & \multirow{4}{*}{ Analgesic given } & 3 \\
\hline & Mild Pain & & 15 \\
\hline & Moderate Pain & & 2 \\
\hline & Severe Pain & & 10 \\
\hline \multirow{4}{*}{ At 6 Hours } & No Pain & \multirow{4}{*}{ Analgesic given } & \multirow{4}{*}{ Analgesic given } \\
\hline & Mild Pain & & \\
\hline & Moderate Pain & & \\
\hline & Severe Pain & & \\
\hline
\end{tabular}




\section{DISCUSSION}

The hemodynamic responses to laryngoscopy and intubation, comprising elevation in heart rate, systolic and diastolic pressure, are well known. The potential for life threatening complications associated with these responses is also well documented. Therefore, it has become imperative to develop a novel technique to prevent these potentially hazardous responses ${ }^{[1]}$. The measures for controlling these hemodynamic responses aim to stabilize heart rate and blood pressure during laryngoscopy and intubation in order to prevent any rise in myocardial work load and oxygen demand as well as to preserve the perfusion of vital organs ${ }^{[2,3]}$. At the same time, safety of such techniques is also a prime concern. It is desirable to use a drug with least numerous, rapidly recognizable and easily treatable adverse effects. It is also desirable that the procedure should be simple so that it can be recommended as a routine practice. The hemodynamic responses to laryngoscopy and tracheal intubation from reflex sympathetic discharge result from epipharyngeal stimulation ${ }^{[3]}$. It is logical to select an agent which would prevent or minimize the laryngopharyngeal stimulation by the intubation process or an agent which would block the sympathetic activity associated with it. Opioids act as agonists on opioid receptors, located in those areas of the brain and spinal cord that are involved with pain perception, integration of pain impulses and responses to pain. The principal effect of opioid receptor activation is a decrease in neurotransmission and thus, pain suppression. Fentanyl suppresses the nociceptive stimulation and centrally decreases the sympathetic tone ${ }^{[4]}$. The hemodynamic stability with magnesium sulfate could be attributed to its antagonistic activity on $\mathrm{Ca}^{++}$and NMDA receptor or inhibition of catecholamine release or vasodilatory effect of the ion or a combination of all these ${ }^{[5]}$. Magnesium sulfate in several studies is shown to reduce the requirement of narcotics for postoperative pain due to analgesic and coanalgesic effects ${ }^{[5]}$.
There was no statistically significant difference between the groups with regard to age, weight, sex, systolic and diastolic, mean blood pressure ( $>00.05)$. So, both the groups were considered to be of comparable parameters. It was observed that 5 min. after study drug, pulse rate decreased in $\mathrm{F}$ group (insignificantly) but increased significantly in $M$ group (9.99\%), Mean change in pulse rate after intubation was more for M Group, Pulse rate reached near baseline value at 5 minutes after intubation in $\mathrm{F}$ group, while in $10 \mathrm{~min}$. after intubation in $\mathrm{M}$ group. Our results are in accordance with Puri GD, et al (1998) who also observed increase in pulse rate after Magnesium sulfate which further increased after intubation.Jee D, et al (2009) found that i.v. Magnesium sulphate, given before pneumoperitoneum, attenuates arterial pressure increase during laparoscopic cholecystectomy, apparently due to reductions in the release of catecholamine, vasopressin, or both ${ }^{[4]}$.

It was observed that $5 \mathrm{~min}$. after study drug, $\operatorname{SBP}(0.03 \%), \quad \operatorname{DBP}(0.02 \%), \quad \operatorname{MAP}(0.61 \%)$ decreased in $\mathrm{F}$ group (insignificantly) but decreased significantly in M group - SBP (1.29\%), DBP(9.99\%), MAP (1.96\%). Mean change in SBP, DBP, MAP after intubation was more for M Group. DBP reached near baseline value at 5 minutes after intubation in both the group. SBP reached near baseline value at 10 minutes after intubation in both the groups. MAP reached near baseline value at 5 minutes after intubation in $\mathrm{F}$ group, while in $10 \mathrm{~min}$. after intubation in $\mathrm{M}$ group. James Michael FM, et al (1989) also observed a rise in blood pressure after intubation in patient pretreated with I.V. Magnesium sulfate. Elsharnouby NM, et al (1996) administered i.v. magnesium sulphate as a technique of hypotensive anaesthesia. The mean time to $1^{\text {st }}$ analgesic request (in minutes) was $29.50 \pm 8.84$ in group $\mathrm{F}$ and $187.33 \pm 19.55$ in $\mathrm{M}$ group. Thus, it was observed that there was clinically and statistically highly significant difference between the post operative analgesic duration between the two groups ( $p<0.05$ ); and the post operative analgesia 
of Magnesium sulfate was far better than that of fentanyl citrate. Asokumar Buvanendran, et al (2002) stated that for patients receiving spinal analgesia for labor, the addition of magnesium sulfate to the opioid fentanyl prolongs analgesia with no increase of side effects. Similarly, Koinig $\mathrm{H}$, et al (1998) observed that i.v. magnesium sulfate administration reduces intraoperative and postoperative analgesic requirements and magnesium can be an adjuvant to perioperative analgesic management.

We started to note the adverse effects after Fentanyl or Magnesium injection and recorded up to 6 hours postoperatively. The incidence of nausea and shivering was found more in M Group while the incidence of postoperative vomiting, sedation and restlessness was more in F Group. But these adverse effects were statistically insignificant in both the groups and did not require any supplementary management. Walter $S$ Nimmo, et al (1985) found that patients in the higher dose of fentanyl demanded less I.M. Morphine and had better pain relief after operation, without important respiratory depression.

\section{CONCLUSION}

Thus, Magnesium sulfate provides intraoperative hemodynamic stability like Fentanyl citrate; although the hemodynamic stability provided by Magnesium sulfate is not superior to that provided by the potent short acting opiate- Fentanyl citrate. Also, the use of opiate has been associated with some side effects like respiratory depression, PONV etc. Patients receiving Magnesium sulfate during perioperative period have better pain relief and fewer requirements of rescue analgesics in the early postoperative period, without any major side effects.

To conclude, Magnesium sulfate provides intraoperative hemodynamic stability like Fentanyl citrate, though not superior to that provided by Fentanyl citrate. However, considering the better perioperative analgesic effect, relatively less incidence of side effects, its less cost and easy availability, Magnesium sulfate can be considered as a useful and good alternative to Fentanyl citrate, especially in circumstances, where the complications associated with opioids are undesirable.

\section{REFERENCES}

1. Allen RW, James MFM and Uys PC. Attenuation of the pressor response to tracheal intubation in hypertensive proteinuric pregnant patients by lignocaine, alfentanil and Magnesium sulphate. Br. J. Anaesth. (1991) 66(2): 216-223.

2. Althaus JS, Miller ED, Moscickii JL et al. Analgesic contribution of sufentanil during Halothane anesthesia. A mechanism involving serotonin. Anesth. Analg. 1985; 64:857.

3. Altura BM and Altura BT. Magnesium and Vascular Tone and Reactivity. Blood Vessels 1978;15:5-16.

4. Asokumar Buvanendran, Robert J. McCarthy, Jeffrey S. Kroin, Warren Leong, Patricia Perry and Kenneth J Tuman. Intrathecal Magnesium Prolongs Fentanyl Analgesia. Anesth Analg September 2002 95:661-666.

5. Baker SB and Worthley IIG. The essentials of calcium, Magnesium and phosphate metabolism. Prog cardiovasc dis 1993; 35:271-310.

6. Black TE, Kay B and Healy TE. Reducing the haemodynamic responses to laryngoscopy and intubation: A comparison of alfentanil with Fentanyl. Anaesthesia1984; Sep;39(9):883-7.

7. Brill S, Sedgwick PM, Hamann W and Di Vadi PP. Efficacy of intravenous Magnesium in neuropathic pain. $\mathrm{Br} \mathrm{J}$ Anaesth 2002; 89: 711-14.

8. Bruder N, Ortega D and Granthil C. Consequences and preventive methods of hemodynamic changes during laryngoscopy and intratracheal intubation. Ann Fr Anesth Reanim 1992;11:57-71. 
9. Chang HM, Berde CB and Holz GY. Sufentanil, morphine, metenkephalin, and k-agonist (U-50, 488H) inhibit substance P release from primary sensory neurons. A model for presynaptic spinal opioid actions. Anesthesiology 1989; 70:672.

10. Choi JC, Yoon KB, Um DJ, Kim C, Kim JS and Lee SG. Intravenous Magnesium sulfate administration reduces Propofol infusion requirements during maintenance of Propofol-N2O anesthesia: part I: comparing Propofol requirements according to hemodynamic responses: part II: comparing bispectral index in control and Magnesium groups. Anesthesiology 2002;97: 1137-41.

11. Cousins MJ, Mather LE. Intrathecal and epidural administration of opioids. Anesthesiology 1984; 27:8-12.

12. Curran J, Crowley $M$ and Sullivan GO. Droperidol and endotracheal intubation: Attenuation of pressure response to laryngoscopy and intubation. Anaesthesia, 1980; 35: 290 -294.

13. Walter S Nimmo and Gordon J Todd. Fentanyl by constant rate I.V. infusion for postoperative analgesia. $\mathrm{Br} \mathrm{J}$ Anaesth 1985; 57(3): 250-254.

14. Puri GD, Marudhachalam KS, Chari Pramila and Suri RK. The effect of Magnesium sulphate on haemodynamics and its efficacy in attenuating the response to endotracheal intubation in patients with coronary artery disease. Anesth Analg 1998;87:808-11.

15. Koing H, Wallner T, Marhofer P, Andel H, Hörauf $\mathrm{K}$ and Mayer $\mathrm{N}$. Magnesium sulfate reduces intra- and postoperative analgesic requirements. Anesth Analg July 1998 87:206-210.

16. James Michael FM, Beer Eryk R and Esser Jan D. Intravenous Magnesium sulfate inhibits catecholamine release associated with tracheal intubation. Anesth Analg June 1989 68:772-776.
17. Elsharnouby NM and Elsharnouby MM. Magnesium sulphate as a technique of hypotensive anaesthesia. Br. J. Anaesth. 1996(6): 727-731. 